\title{
Protective Effect of Opuntia dillenii Haw Fruit against Lead Acetate-Induced Hepatotoxicity: In Vitro and In Vivo Studies
}

\author{
Reza Shirazinia, ${ }^{1}$ Ali Akbar Golabchifar, ${ }^{1}$ Vafa Baradaran Rahimi, ${ }^{2}$ Abbas Jamshidian, ${ }^{3}$ \\ Alireza Samzadeh-Kermani, ${ }^{4}$ Parisa Hasanein, ${ }^{5}$ Mohammadreza Hajinezhad (D), \\ and Vahid Reza Askari $\mathbb{D}^{2,7,8}$ \\ ${ }^{1}$ Department of Comparative Biosciences, Faculty of Veterinary Medicine, University of Tehran, Tehran, Iran \\ ${ }^{2}$ Applied Biomedical Research Center, Mashhad University of Medical Sciences, Mashhad, Iran \\ ${ }^{3}$ Pathobiology Department, Veterinary Faculty, University of Zabol, Zabol, Iran \\ ${ }^{4}$ Chemistry Department, Basic Science Faculty, University of Zabol, Zabol, Iran \\ ${ }^{5}$ Department of Biology, School of Basic Sciences, University of Zabol, Zabol, Iran \\ ${ }^{6}$ Department of Basic Science, School of Veterinary Medicine, University of Zabol, Zabol, Iran \\ ${ }^{7}$ Department of Pharmaceutical Sciences in Persian Medicine, School of Persian and Complementary Medicine, \\ Mashhad University of Medical Sciences, Mashhad, Iran \\ ${ }^{8}$ Department of Persian Medicine, School of Persian and Complementary Medicine, Mashhad University of Medical Sciences, \\ Mashhad, Iran
}

Correspondence should be addressed to Mohammadreza Hajinezhad; hajinezhad@uoz.ac.ir and Vahid Reza Askari; askariv@ mums.ac.ir

Received 27 November 2020; Revised 23 March 2021; Accepted 26 March 2021; Published 30 April 2021

Academic Editor: Sandrina A. Heleno

Copyright ( 12021 Reza Shirazinia et al. This is an open access article distributed under the Creative Commons Attribution License, which permits unrestricted use, distribution, and reproduction in any medium, provided the original work is properly cited.

Lead is one of the most common environmental contaminants in the Earth's crust, which induces a wide range of humans biochemical changes. Previous studies showed that Opuntia dillenii (OD) fruit possesses several antioxidant and anti-inflammatory properties. The present study evaluates $O D$ fruit hydroalcoholic extract (OHAE) hepatoprotective effects against lead acetate- $(\mathrm{Pb}-)$ induced toxicity in both animal and cellular models. Male rats were grouped as follows: control, $\mathrm{Pb}(25 \mathrm{mg} / \mathrm{kg} / \mathrm{d}$ i.p.), and groups 3 and 4 received $O H A E$ at 100 and $200 \mathrm{mg} / \mathrm{kg} / \mathrm{d}+\mathrm{Pb}(25 \mathrm{mg} / \mathrm{kg} / \mathrm{d}$ i.p.), for ten days of the experiment. Thereafter, we evaluated the levels of alkaline phosphatase (ALP), alanine aminotransferase (ALT), and aspartate aminotransferase (AST), catalase (CAT) activity and malondialdehyde (MDA) in serum, and liver histopathology. Additionally, the cell study was also done using the HepG2 cell line for measuring the direct effects of the extract on cell viability, oxidative stress MDA, and glutathione (GSH) and inflammation tumor necrosis factor- $\alpha$ (TNF- $\alpha$ ) following the Pb-induced cytotoxicity. Pb significantly increased the serum levels of ALT, AST, ALP, and MDA and liver histopathological scores but notably decreased CAT activity compared to the control group ( $p<0.001$ for all cases). OHAE (100 and $200 \mathrm{mg} / \mathrm{kg}$ ) significantly reduced the levels of serum liver enzyme activities and MDA as well as histopathological scores while it significantly increased CAT activity compared to the $\mathrm{Pb}$ group $(p<0.001-0.05$ for all cases). OHAE $(20,40$, and $80 \mu \mathrm{g} / \mathrm{ml})$ concentration dependently and significantly reduced the levels of MDA and TNF- $\alpha$, while it increased the levels of GSH and cell viability in comparison to the $\mathrm{Pb}$ group $(p<0.001-0.05$ for all cases). These data suggest that OHAE may have hepatoprotective effects against $\mathrm{Pb}$-induced liver toxicity both in vitro and in vivo by its antioxidant and anti-inflammatory activities.

\section{Introduction}

Lead $(\mathrm{Pb})$ is the most common environmental contaminants in the Earth's crust, which can induce a wide range of toxicity, including biochemical, physiological, and behavioral changes in humans by multiple mechanisms [1]. Indeed, lead pollution and poisoning are common problems in industrial and developing countries [2]. Heavy metals, 
especially lead, are highly stable in the environment and can be concentrated in the food chains [3]. World health organization (WHO) recently declared that, based on 20162017 reports, lead intoxication is responsible for more than one million deaths throughout the world, with the highest burdens in the developing countries. Based on the Institute for Health Metrics and Evaluation (IHME), about $63.2 \%$ of idiopathic developmental, intellectual disabilities, $10.3 \%$ of hypertensive heart diseases, $5.6 \%$ of ischemic heart diseases, and $6.2 \%$ of strokes were related to lead exposure [4]. Lead is present in every food grain and can enter the body through drinking contaminated water or breathing polluted air. Even some cosmetics may contain tiny amounts of lead; therefore, lead pollution exists in every aspect of our daily life [5].

The central nervous system, hematopoietic system, liver, and kidney systems are the considered main targets of lead toxicity. Lead enters the body by different routes, through eating (main route) or inhalation, and then, it is circulated via blood and stored in the soft tissues and bone $[6,7]$. Even continuous exposure to low levels of lead acetate as $1.0 \mu \mathrm{g} / \mathrm{g}$ can affect the levels of intelligence, behavior, attention, and growth $[7,8]$. It has been shown that the liver cannot metabolize lead acetate and also excrete it adequately; therefore, this metal is distributed in the body and gradually accumulated in the various organs, including bone, muscle, brain, liver, kidney, hematopoietic system, central nervous system, and gastrointestinal tract [9]. Contextually, lead accumulation in the body causes several impairments and imbalances in the body, including oxidants and antioxidants, and immunity systems [10, 11]. Lead-induced oxidative stress in blood and other tissues is the major mechanism of lead toxicity [12]. Moreover, lead intoxication causes activation of inflammatory cells that may provoke inflammation and related diseases $[13,14]$. Indeed, lead exposure causes a significant increase in the level of blood inflammatory biomarkers, including interleukin $1-\beta$ (IL-1 $\beta$ ), interleukin-6 (IL-6), and TNF- $\alpha$ [15]. Chronic lead poisoning is not detectable in $29 \%$ of patients, but hypertension, gout, chronic renal failure, and hypothyroidism and impotence are considered important diagnosis factors [16-18].

Opuntia dillenii $(O D)$, a member of Cactaceae (Figure 1), is widely grown in tropical/subtropical areas such as China, India, and Iran [19-21]. People in Asia have adopted $O D$ as a medicinal plant. In India, it is used to treat gastrointestinal disease, pimples, and syphilis [22]. Several ingredients, including polyphenols, polysaccharides, flavonoids, dietary fibers, and vitamin C (ascorbic acid), have been isolated from the fruits of $O D$ [23]. OD's protective effect and the other plants of Opuntia species have been investigated against heavy metal-induced toxicity in previous studies $[20,21]$. Moreover, $O D$ has shown the potential bioabsorption and removal capacity against heavy metals intoxication [24-26]. Previous studies also have indicated $O D$ as a plant with desirable pharmacologic properties including anti-inflammatory and immunomodulatory [27, 28], antioxidant [29], neuroprotective [30], antidiabetic [31], analgesic [28], antitumor [32], hypotensive [33], antimicrobial [34], and hepatoprotective effects [34]. Loro et al. reported that intraperitoneal (i.p.) administration of $O D$ ameliorates carrageenan-induced rat paw edema as a model of inflammation in a dose-dependent manner [28]. Moreover, crude polysaccharides obtained from $O D$ possessed antioxidant properties evidenced by DHPP assay [29]. Hitherward, there is no report regarding the protective effects of $O D$ against heavy metal-induced liver, oxidative, and inflammatory damages. Therefore, we investigated OD fruit extract's possible protective effect on lead-induced hepatotoxicity, oxidative stress, and inflammation in both in vivo and in vitro models.

\section{Material and Methods}

2.1. Drugs and Chemicals. Ethanol was purchased from Sigma (USA). Lead acetate was purchased from Merck (Germany). Aspartate transaminase (AST), alanine aminotransferase (ALT), and alkaline phosphatase (ALP) kits were purchased from Pars Azmoon Company (Tehran, Iran). TBARS assay kit was provided from BioAssay Systems (Hayward, CA 94545, USA). Catalase (CAT), glutathione (GSH), and malondialdehyde (MDA) assay kits were purchased from ZellBio (Germany). HepG2 cell line was from Pasteur Institute (Tehran, Iran). Dulbecco's Modified Eagle Medium (DMEM)/F12 culture media, penicillin, and streptomycin (pen/strep), amphotericin B, fetal bovine serum (FBS), and L-glutamine were purchased from SigmaAldrich Chemical Co. (St. Louis, MO, USA). TNF- $\alpha$ assay kit was purchased from Bender Med (Germany). All other materials were analytical and cell culture grade was provided from Sigma-Aldrich Chemical Co. (St. Louis, MO, USA).

\subsection{Plant Material}

2.2.1. Preparation of the Extracts. $O D$ (Nagphana) fresh fruits were collected from a local market in May 2017 from Zahedan, Sistan, and Baluchestan Province, Iran. The plant was identified by Mrs. Sozani, and the voucher samples were deposited in the School of Pharmacy herbarium, Mashhad University of Medical Sciences, Iran (No. 13161).

Extraction was conducted based on the method described by previous studies with slight modification $[35,36]$. The seeds were removed, and the fresh pulps of fruits were air-dried at room temperature $(26 \pm 1)$ in the shadow and then milled into a fine powder using an electric grinder. The powdered fruits were macerated in $500 \mathrm{ml}$ ethanol and water $(50 \% \mathrm{~V} / \mathrm{V})$ at room temperature $\left(26 \pm 1^{\circ} \mathrm{C}\right)$ for 48 hours with occasional shaking. Then, the extracts were filtered out through a filter paper (Whatman ${ }^{\circledR}$ No.4). The resulting liquid was concentrated at $40^{\circ} \mathrm{C}$ in a rotary evaporator and then kept in the incubator $\left(40^{\circ} \mathrm{C}\right)$ to remove organic solvents resulting in the dry powder (the final yield of the procedure was about $13.2 \% \mathrm{w} / \mathrm{w})$.

2.2.2. Total Phenolic Content (TPC) of the Extract. Total phenolic content (TPC) of the extract was measured according to Folin-Ciocalteu (FC) method, which was described previously $[37,38]$ with minor modification. A fraction $(100 \mu \mathrm{l})$ of OD's ethanolic solution $(20 \mu \mathrm{g} / \mathrm{mL})$ was 


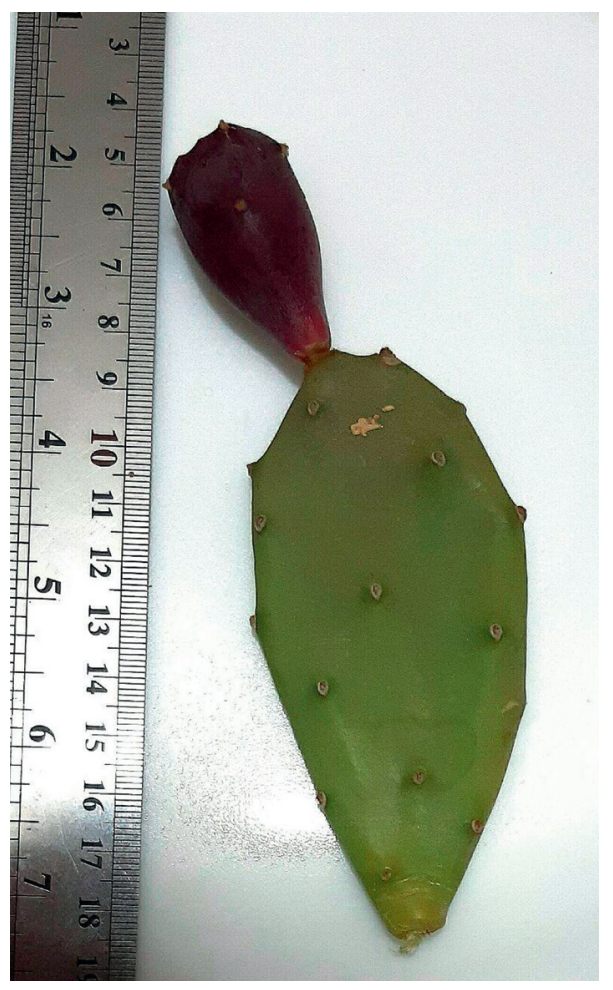

(a)

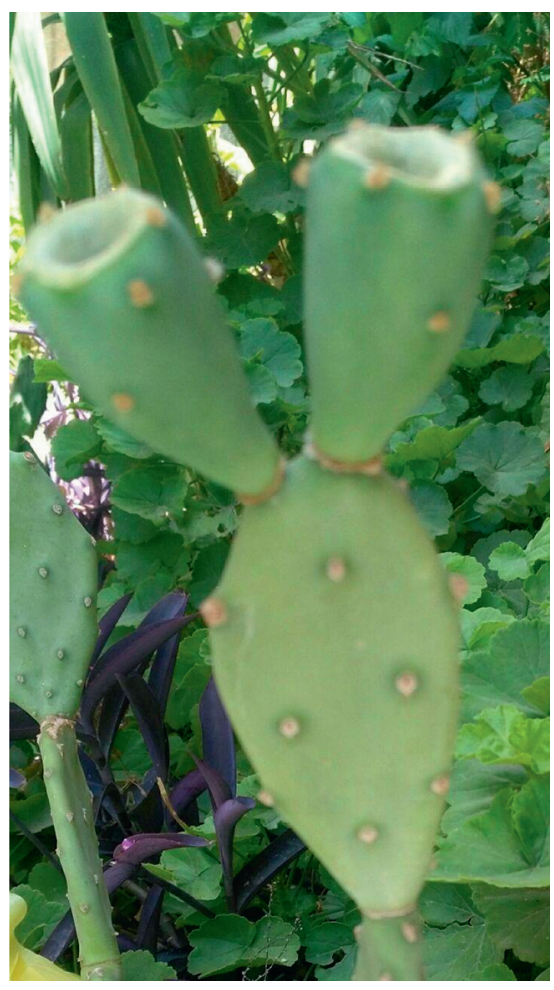

(b)

Figure 1: Opuntia dillenii plant and fruit. The top-right shows the ripe fruit.

mixed with equal water volume in a test tube. Next, about $200 \mu \mathrm{L}$ of FC reagent was augmented to the tube. Following the next $2 \mathrm{~min}, 2600 \mu \mathrm{L}$ of a $5 \%(\mathrm{w} / \mathrm{v})$ sodium carbonate solution was added. The developed color was read at $760 \mathrm{~nm}$ using a MultiSpec UV-Vis spectrophotometer (Shimadzu, Tokyo, Japan). Estimation of phenolic compounds was carried out regarding the polyphenol reference calibration curve of the ethanolic solution of Gallic acid (GA) in a range of 0.5 to $10 \mathrm{mg} / \mathrm{L}$ [38-40]. The amount of TPC was expressed as mg of GA equivalent (GAE) per gram of dry extract. For blank, the same process was performed with $100 \mu \mathrm{l}$ of distilled water instead of extract.

\subsection{In Vivo Study}

2.3.1. Animal Husbandry and Experimental Design. Animal experiments were conducted in the laboratory animal center of the University of Zabol, Zabol, Sistan, and Baluchistan Province, Iran. Twenty-four adult male Wistar rats $(200 \pm 20 \mathrm{~g})$ were used in this study. Rats were housed in the condition of a temperature of about $26 \pm 2{ }^{\circ} \mathrm{C}$, controlled humidity, and a $12 / 12^{\circ} \mathrm{h}$ light/dark cycle. Rats had free access to taped water and a standard laboratory diet (JavanehKhorasan, Iran). The Animal Ethics Committee ethically approved the experimental procedures of the University of Zabol, Zabol, Sistan, and Baluchistan Province, Iran (ethical ID: IR.UOZ.REC.1398.1).

The study protocol was conducted for ten days (first five days premedication + second five days premedication with
$\mathrm{Pb}$ exposure, Figure 2). Animals were randomly and equally divided into four groups of six animals as follows:

(1) Control group received daily distilled water orally (p.o.) for both the first and second 5 days but received physiological saline $(0.9 \% \mathrm{w} / \mathrm{v} \mathrm{NaCl}$, i.p. $)$ at the same volume of other groups daily during the second 5 days of the experiment

(2) $\mathrm{Pb}$ group received daily administration of distilled water (p.o.) for both first and second 5 days and then received lead acetate $(25 \mathrm{mg} / \mathrm{kg}$ b.w/day, i.p.) during the second 5 days of the experiment

(3) OHAE100 received daily administration of OHAE $(100 \mathrm{mg} / \mathrm{kg}$ b./day, p.o.) for both the first and second 5 days and then received lead acetate $(25 \mathrm{mg} / \mathrm{kg} \mathrm{b.w/}$ day, i.p.) during the second 5 days of the experiment

(4) OHAE200 received daily administration of OHAE (200 mg/kg b./day, p.o.) for both the first and second 5 days and then received lead acetate ( $25 \mathrm{mg} / \mathrm{kg}$ b.w/day, i.p.) during the second 5 days of the experiment

Notably, groups 3 and 4 were also injected (i.p.) by $0.5 \mathrm{~mL}$ lead acetate at a dose of $25 \mathrm{mg} / \mathrm{kg} \mathrm{b}$.w./day for the second 5 days combined with $O D$ fruit extract (Figure 2).

The dose of lead acetate was adjusted based on literature reports and preliminary studies [41]. Finally, rats fasted for 12 hours and then anesthetized with diethyl ether, and blood samples were collected by the retroorbital puncture using dry tubes. Blood samples were centrifuged (3000 rpm for 


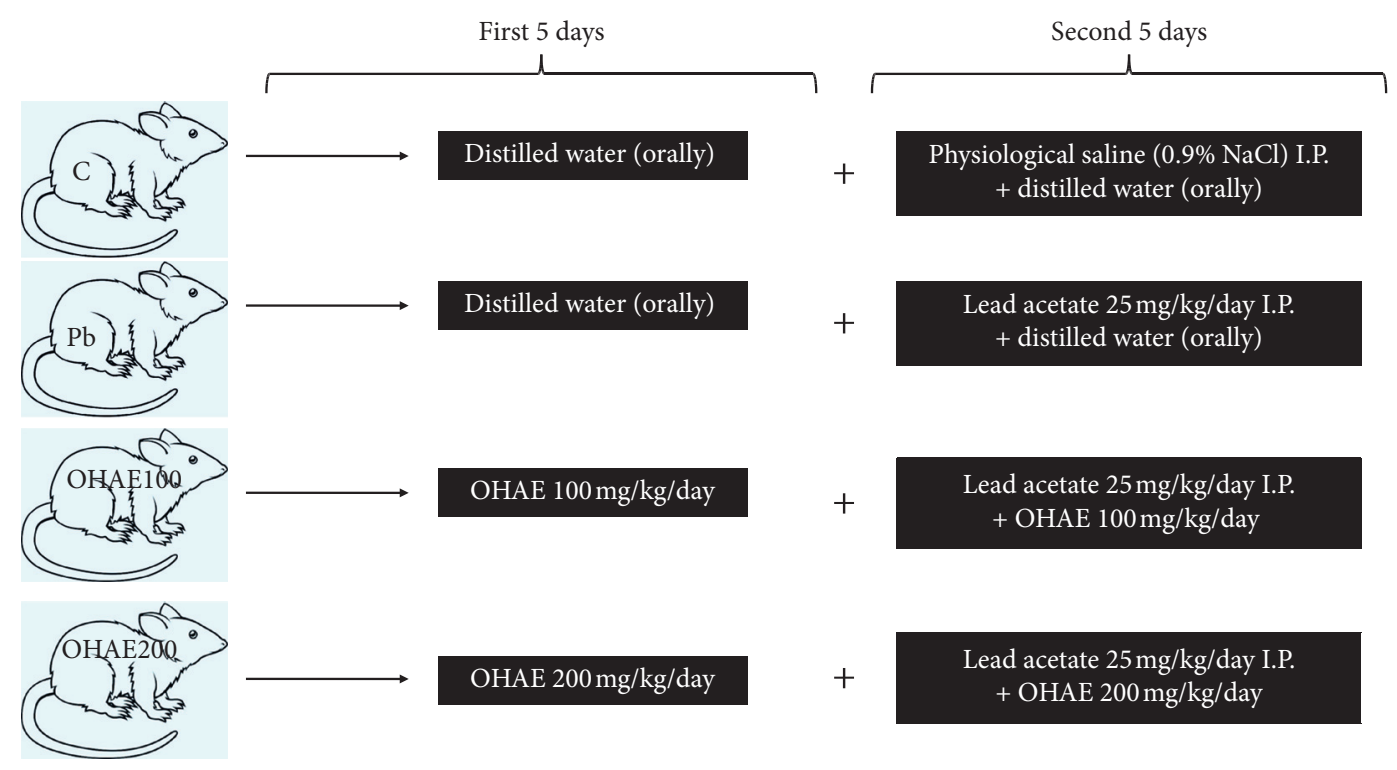

FIgURE 2: schematic diagram of in vivo study procedure.

$5 \mathrm{~min}$ ) for separating the serum. The serum was immediately frozen at $-80^{\circ} \mathrm{C}$ until use $[40,42]$.

2.3.2. Serum Biochemical Parameters. Blood samples were collected using retroorbital puncture, and serum samples were collected as described in the animal husbandry and experimental design section. According to the manufacturer of the kit, the analyses of serum ALT, AST, and ALP levels were performed by relevant commercial kits using the Selectra pro, M autoanalyzer (Vital Scientific, SpanNeren, Netherlands).

2.3.3. Evaluation of Lipid Peroxidation (TBARS and Catalase Activity). MDA level (as TBARS) and catalase activity in serum samples were measured using the relevant commercial biochemistry kits (BioAssay Systems, USA and ZellBio Germany, respectively) according to the manufacturer's instructions.

2.3.4. Histopathological Examination. After euthanasia, liver specimens were sliced and preserved in $10 \%$ formalin and processed for histological staining. After paraffin embedding and block making, serial sections were stained with hematoxylin-eosin and evaluated (Olympus, Tokyo, Japan) at 20,40, and 100 magnifications. Liver sections were numerically graded from 0 to 4 , covering no liver injuries to severe lead-induced hepatic injuries such as cytoplasmic vacuolation, cell necrosis, sinusoidal dilation, and hemorrhage based on the method previously described (Table.1) [43]. Afterward, histopathological grading data was statistically tested using the Kruskal-Wallis test analysis followed by the post hoc Dunn's multiple comparisons.

\subsection{In Vitro Study}

2.4.1. Cell Culture. The cells were cultured in DMEM/F12 plus $1 \% \mathrm{v} / \mathrm{v}$ of Pen/Strep $(100 \times)$ and $10 \% \mathrm{v} / \mathrm{v}$ of heat- inactivated FBS supplemented with $0.5 \mu \mathrm{g} / \mathrm{mL}$ amphotericin $\mathrm{B}$ and two $\mathrm{mML}$ glutamine (all from Invitrogen, Carlsbad, CA, USA) under the condition of $37^{\circ} \mathrm{C}$ and $5 \% \mathrm{v} / \mathrm{v} \mathrm{CO}_{2}$, in a humidified incubator.

2.4.2. Cell Viability. The effect of various concentrations of the extract on cell viability was examined using MTT (3- $(4,5-$ dimethyl-2-thiazolyl)-2,5-diphenyl-2H-tetrazolium bromide) proliferation assay color. Five thousand HepG2 cell lines were grown in a 96-well plate and treated with different concentrations of the extract at a range of $0-160 \mu \mathrm{g} / \mathrm{ml}$ for 48 hours. Due to the hardy solubility of the extract at $160 \mu \mathrm{g} / \mathrm{ml}$, we used a lower concentration of the extract $(80 \mu \mathrm{g} / \mathrm{ml})$ as the highest concentration for the study. Furthermore, another design was also done to evaluate the extract's protective impact on lead acetate-induced cell death. In review, the cells were pretreated at concentrations of $0-80 \mu \mathrm{g} / \mathrm{ml}$ for 24 hours and then subjected to $100 \mu \mathrm{g} / \mathrm{ml}$ of lead acetate [44] for a further 24 hours of coincubation. Afterward, $10 \mu \mathrm{l}$ of MTT reagent $(5 \mathrm{mg} / \mathrm{ml})$ was added to each well incubated for the next 3 hours. Formazan crystals were dissolved in $100 \mu \mathrm{L}$ DMSO, and the absorbance was read using StatFAX 2100 ELISA plate reader (Awareness Inc, USA) at $570 \mathrm{~nm}$ in referencing $620 \mathrm{~nm}$. The assay was carried out six times and replicated three times for each sample [13, 45]. The final concentration of DMSO, as cosolvent, was lower than $0.1 \%$ $\mathrm{v} / \mathrm{v}$ for all experiments.

2.4.3. Evaluation of Total Glutathione (GSH), Lipid Peroxidation (MDA), and Inflammatory Cytokine (TNF- $\alpha$ ). GSH and MDA levels were measured using the relevant commercial biochemistry kits (ZellBio, Germany) according to the manufacturer's instructions [42]. As indexes of inflammation, TNF-a was also measured using the relevant ELISA kit (Bender Med, Germany). In brief, the cells were cultured at a density of 5,000,000 cells/mL overnight. Next, 
TABLE 1: Pathological scoring approaches for liver injury based on the previously described by Abu-Amara et al. [43].

\begin{tabular}{cc}
\hline Score & Definition \\
\hline 0 & Minimal or no evidence of injury \\
1 & Mild injury, including cytoplasmic vacuolization and focal nuclear pyknosis \\
2 & A moderate injury such as cytoplasmic vacuolization, areas of hepatocyte ballooning no necrosis, sinusoidal dilatation, and \\
congestion, as well as the blurring of intercellular borders
\end{tabular}

the cells were pretreated via different concentrations $(20-80 \mu \mathrm{g} / \mathrm{ml})$ of the extract for 24 hours and subsequently were exposed to $100 \mu \mathrm{g} / \mathrm{ml}$ of lead acetate for an additional 24 hours. Finally, the supernatants were separated for measuring each indicator using the manufacturer's instructions of the kit.

2.5. Statistical Analysis. Statistical analysis was performed using GraphPad Prism 8 for Windows (San Diego, CA). Data of oxidative stress and inflammation markers were expressed as mean \pm standard deviation (SD) and analyzed by one-way analysis of variance (ANOVA) followed by Tukey's posttest. For the evaluation of histopathological scores, nonparametric analysis Kruskal-Wallis test was performed with the post hoc Dunn's multiple comparisons test and expressed as mean with range. Statistical significance was accepted at $p \leq 0.001,0.01$, and 0.05 .

\section{Results}

3.1. Total Phenolic Content of the Extract. Generally, the FC method is often utilized for the evaluation of TPC in natural products. The value of TPC for the extract was $65 \mathrm{mg} \mathrm{GAE} / \mathrm{g}$ dried extract.

\subsection{Animal Study}

3.2.1. The Effects of OHAE on the Serum Levels of Liver Function Enzymes. The present data indicated that the treatment with lead acetate significantly increased serum AST, ALT, and ALP activities compared to the control ( $p<0.001$ to 0.01 for all cases). Meanwhile, treatment with both doses of OHAE (100 and $200 \mathrm{mg} / \mathrm{kg}$ b.w/day) markedly decreased these parameters compared to the lead acetate treated group $(p<0.001$ to 0.01 for all cases) (Figures 3(a)$3(\mathrm{c})$ ).

3.2.2. The Effects of OHAE on the Serum Levels of TBARS and Catalase Activity. Treatment with lead acetate significantly decreased serum catalase activity, while it increased serum MDA concentration compared to the control group $(p<0.001$ for all cases, Figure 4(b)). Administration of OHAE (100 or $200 \mathrm{mg} / \mathrm{kg}$ b.w/day) before and during the lead acetate injection reversed these parameters compared with the $\mathrm{Pb}$ group ( $p<0.001$ to 0.01 , Figures $4(\mathrm{a})$ and $4(\mathrm{~b})$ ).
3.2.3. The Effects of OHAE on the Liver Histopathological Scores. The liver sections of lead acetate treated rats showed significant patterns of degenerated hepatic cords and fatty change (FC) (Figure 5(b)), hemorrhage (HR) (Figure 5(c)), sinusoidal dilatation (SD) (Figure 5(d)) as well as hepatic vacuolation (V) (Figure 5(e)), and pyknotic nuclei (PC) (Figure 5(f)) in comparison to the control group, in which normal hepatic cord and central vein architecture were obvious (CV and HC) (Figure 5(a)). Also, histological alterations were markedly reduced by the $O H A E$ at 100 and $200 \mathrm{mg} / \mathrm{kg} / \mathrm{b} . \mathrm{w} /$ day (Figures 5(g) and 5(h), respectively).

Overall, the pathological scores were notably more significant in the $\mathrm{Pb}$ group than in the control group $(p<0.001$, Figure 6). In contrast, treatment with both doses of the extracts reduced the pathological scores compared to the $\mathrm{Pb}$ group, although these reductions were statistically significant only at $200 \mathrm{mg} / \mathrm{kg}$ of the extract compared to the $\mathrm{Pb}$ group $(p<0.01$, Figure 6$)$.

\subsection{Cellular Study}

3.3.1. The Effects of OHAE on the Level of Cell Viability. Our findings demonstrated that different concentrations of the extract $(0-160 \mu \mathrm{g} / \mathrm{ml})$ had no cytotoxicity on the HepG2 cell line (Figure $7(\mathrm{a})$ ). Besides, pretreatment along with all tested concentrations of OHAE $(20-80 \mu \mathrm{g} / \mathrm{ml})$ significantly increased cell viability against lead acetate toxicity $(\mathrm{Pb}$, concentration: $100 \mu \mathrm{g} / \mathrm{ml}$ ) in a concentration-dependent manner in comparison to the $\mathrm{Pb}$-treated group alone $(p<0.001$, for all cases, Figure 7(b)).

3.3.2. The Effects of OHAE on the Levels of Oxidative Stress Indices (GSH and MDA). Incubation with lead acetate $(100 \mu \mathrm{g} / \mathrm{ml})$ led to a significant increment in the level of MDA and significant decrement in the level of GSH compared to the control group $(p<0.001$ for all cases, Figures $8(\mathrm{a})$ and $8(\mathrm{~b})$ ). However, OHAE treatment could significantly alleviate these values in all concentrations for MDA and 40 and $80 \mu \mathrm{g} / \mathrm{ml}$ for GSH compared to the $\mathrm{Pb}$ group ( $p<0.001$ for all cases, Figures $8(\mathrm{a})$ and $8(\mathrm{~b})$ ).

3.3.3. The Effects of OHAE on the Level of Inflammatory Cytokine (TNF- $\alpha)$. Lead acetate $(100 \mu \mathrm{g} / \mathrm{ml})$ caused a significant increase in the level of TNF- $\alpha(p<0.001$, Figure 9$)$. However, OHAE treatment significantly reduced this 


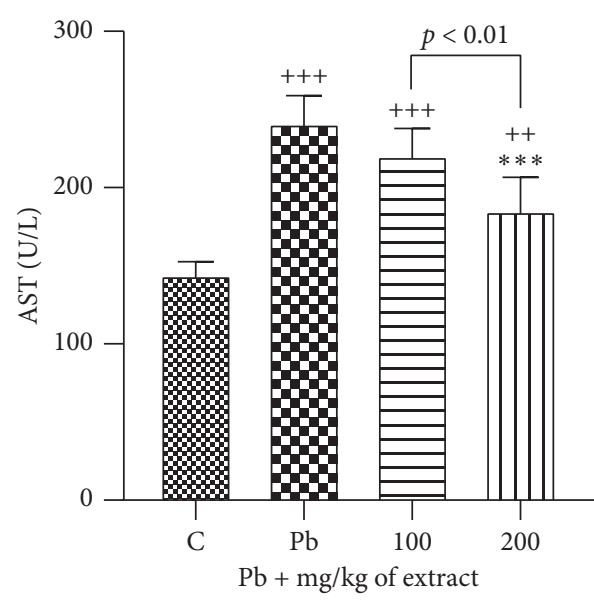

(a)

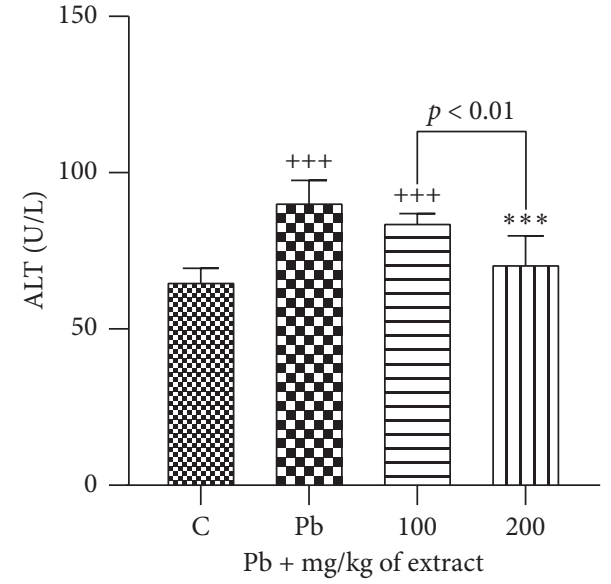

(b)

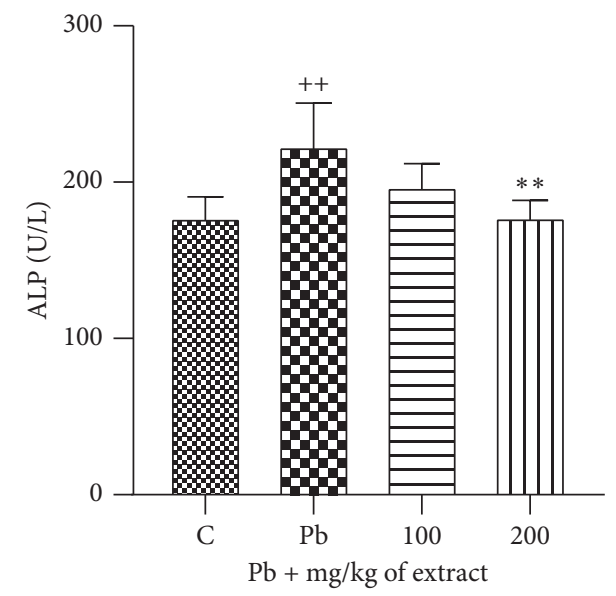

(c)

FIGURE 3: Effect of OHAE at 100 and $200 \mathrm{mg} / \mathrm{kg}$ on the activity levels of liver enzymes (a) AST, (b) ALT, and (c) ALP, following the lead toxicity. Values are expressed as mean $\pm \mathrm{SD} .{ }^{* *} p<0.01,{ }^{* * *} p<0.001$ compared to $\mathrm{Pb}$ group ${ }^{++} p<0.01,{ }^{+++} p<0.001$ compared to control group. The lines represent comparisons between extract treated groups.

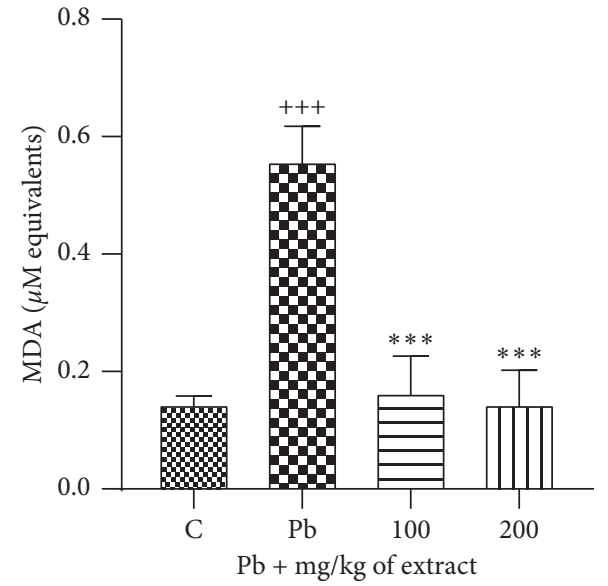

(a)

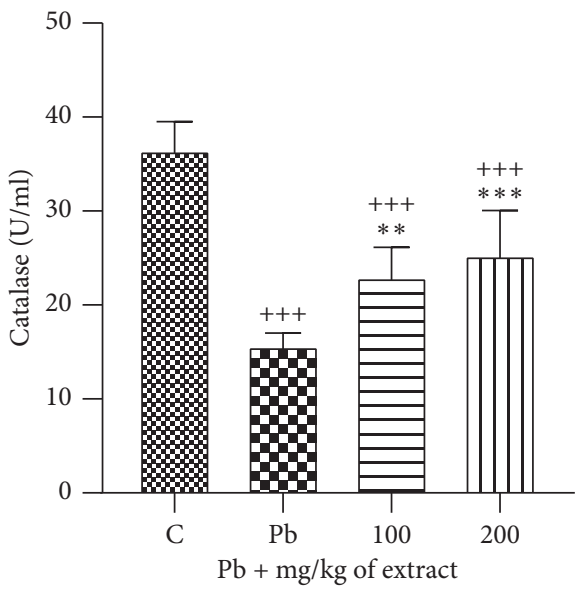

(b)

FIGURE 4: Effect of OHAE at 100 and $200 \mathrm{mg} / \mathrm{kg}$ on the levels of oxidant and antioxidant parameters: (a) MDA concentration and (b) catalase (CAT) activity, respectively, following lead toxicity. Values are expressed as mean $\pm \mathrm{SD}$. ${ }^{* *} p<0.01$ and ${ }^{* * *} p<0.001$ compared to $\mathrm{Pb}$ group; ${ }^{+++} p<0.001$ compared to control group. The lines represent comparisons between extract treated groups. 


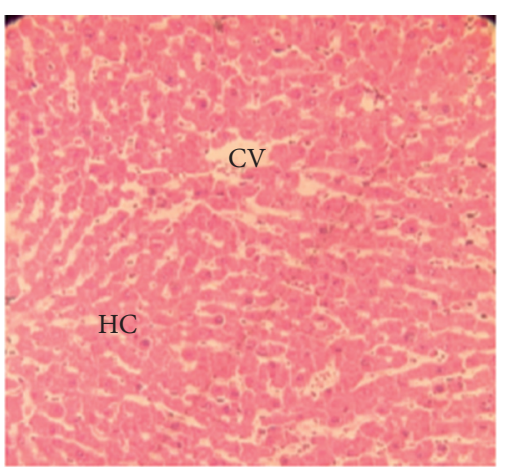

(a)

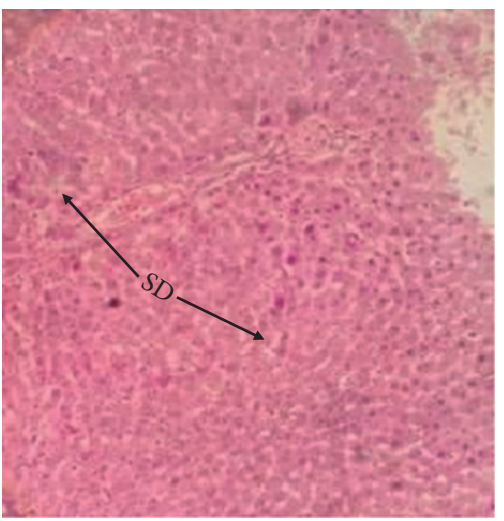

(d)

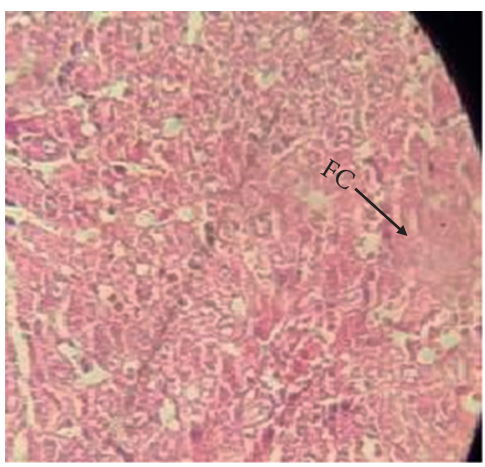

(b)

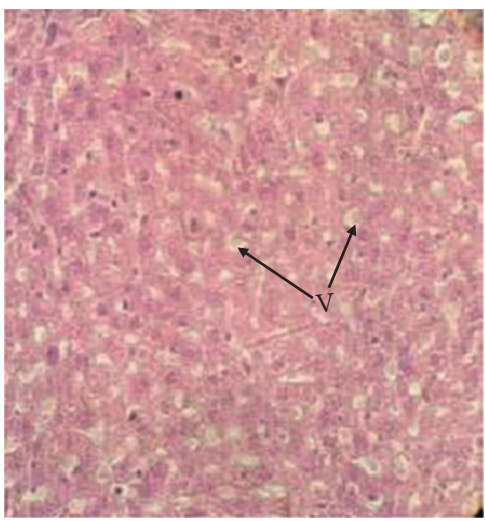

(e)

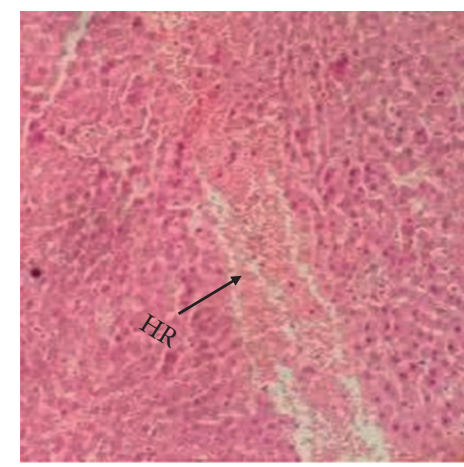

(c)

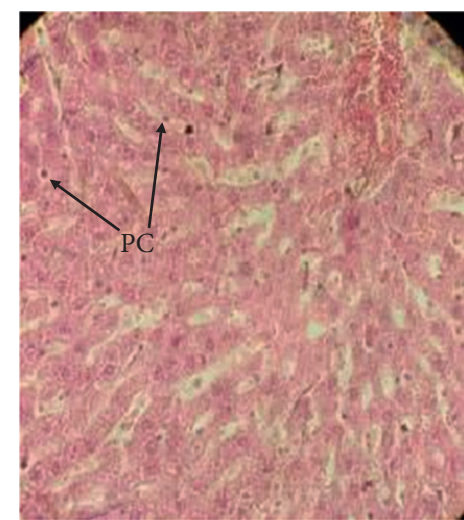

(f)

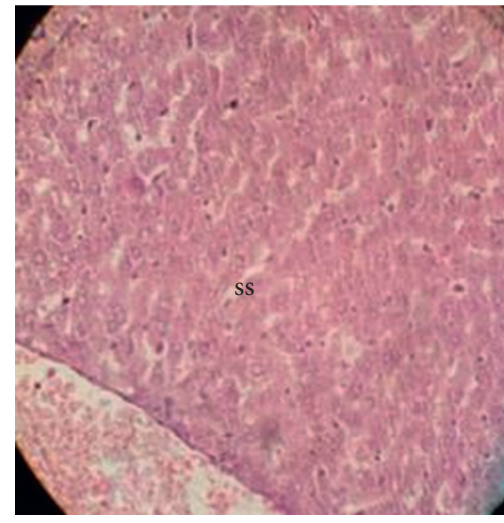

(g)

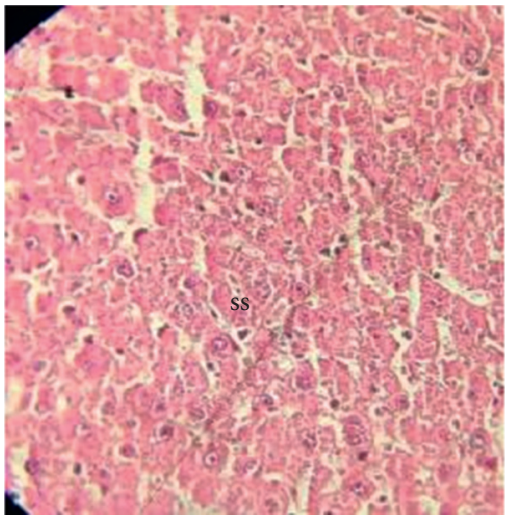

(h)

Figure 5: Paraffin sections stained by hematoxylin and eosin $(\mathrm{H} \& \mathrm{E} \times 20$ and $\times 40)$ for histopathological examination of liver tissues of rats as follows: normal hepatocytes architecture and sinusoids $(\mathrm{HC})$ and central vein $(\mathrm{CV})$ in the control group $((\mathrm{a}) \times 20)$. Alterations in liver tissue including fatty change (FC) $((\mathrm{b}) \times 40)$ and hemorrhage $(\mathrm{HR})((\mathrm{c}) \times 20)$ as well as the degenerated cells with sinusoidal dilatation $(\mathrm{SD})((\mathrm{d})$ $\times 20)$, cytoplasmic vacuolation $(\mathrm{V})((\mathrm{e}) \times 40)$, and pyknotic nuclei $(\mathrm{PC})((\mathrm{f}) \times 40)$ in $\mathrm{Pb}$ group. Reduction in lead-induced alterations resulted in regeneration of normal sinusoidal structures $(\mathrm{SS})((\mathrm{g}) \times 40)$ in the OHAE100 and $((\mathrm{h}) \times 40)$ in the OHAE200 groups.

inflammatory marker at 40 and $80 \mu \mathrm{g} / \mathrm{ml}$ in comparison to the control group $(p<0.001$ for all cases, Figure 9$)$.

\section{Discussion}

To the best of our knowledge, this is the first study that examined the protective impacts of $O H A E$ against lead acetate-induced liver toxicity by both animal and cellular evaluations. In this study, we evaluated lead acetate-induced hepatotoxicity and the protective impact of OHAE at 100 and $200 \mathrm{mg} / \mathrm{kg}$ through its antioxidant properties in vivo and antioxidant and anti-inflammatory characteristics in vitro. Briefly, our results showed that lead acetate caused liver injuries in both models, while the extract could retrieve the injuries.

Lead poisoning is known as a significant health problem in the world, especially in developing countries. Despite the enormous operational processes accomplished to control this burden, cases of lead toxicity still are observed [16]. Exposure to continuous and even low lead levels can exert 


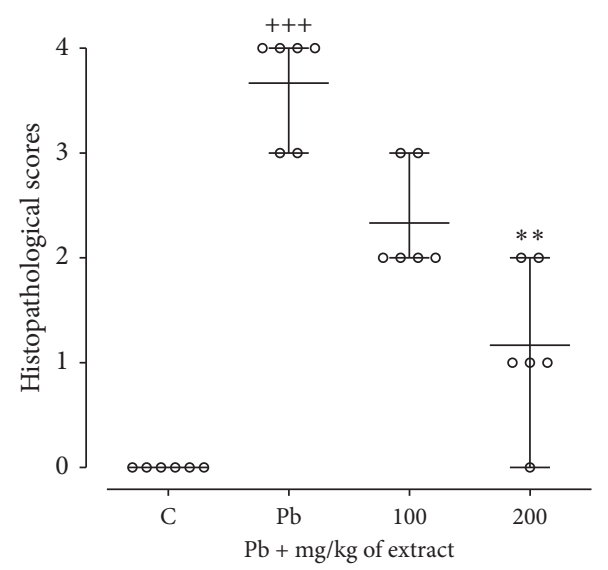

FIgURE 6: The histopathological score of liver injuries. Data are expressed as scatter dot plots and mean with range according to the nature of data (nonparametric). Accordingly, a nonparametric analysis Kruskal-Wallis test was performed with the post hoc Dunn's multiple comparisons test ( $n=6$ per group). ${ }^{+++} p<0.001$ compared to the control group. ${ }^{* *} p<0.01$ compared to the $\mathrm{Pb}$ group.

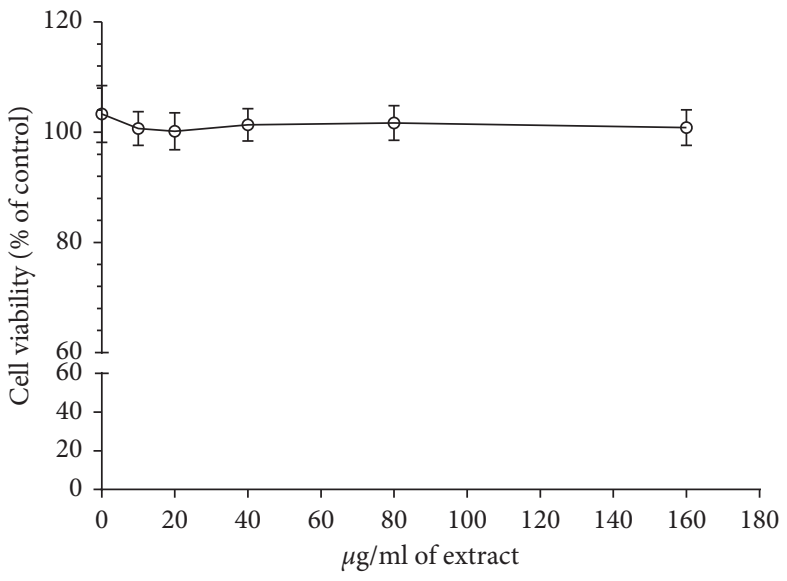

(a)

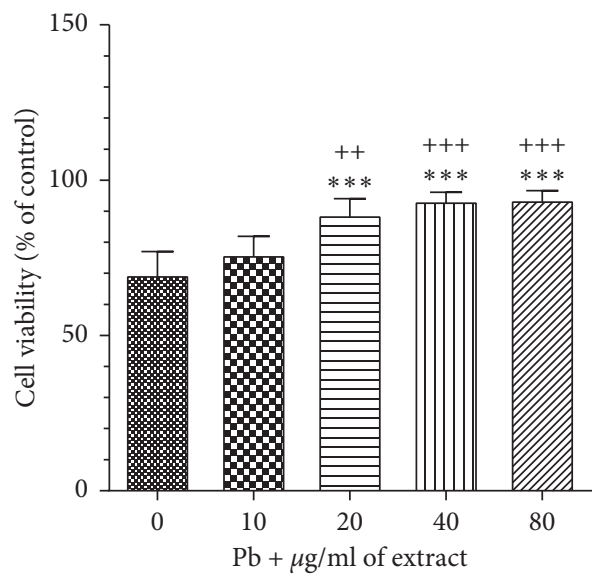

(b)

Figure 7: The effect of OHAE on HepG2 cell viability in the absence (a) and presence of lead acetate- (Pb-) induced hepatotoxicity (concentration: $100 \mu \mathrm{g} / \mathrm{ml},(\mathrm{b})$ ). In Figure 7(a), five thousand HepG2 cell lines were grown in a 96-well plate and treated with different concentrations of the extract at a range of $0-160 \mu \mathrm{g} / \mathrm{ml}$ for 48 hours. In Figure $7(\mathrm{~b})$, the cells were pretreated at concentrations of $0-80 \mu \mathrm{g} / \mathrm{ml}$ for 24 hours and then subjected to $100 \mu \mathrm{g} / \mathrm{ml}$ of lead acetate for a further 24 hours of coincubation. ${ }^{* * *} p<0.001$ compared to the group without extract. ${ }^{++} p<0.01$ and ${ }^{+++} p<0.001$ compared to the group incubated with $10 \mu \mathrm{g} / \mathrm{ml}$ of extract.

liver, kidney, reproductive, and behavioral impairment, but it has been proved that the liver is the most susceptible organ to lead intoxication [46-49]. We observed that lead acetate significantly increased the serum levels of AST, ALP, and ALT compared to the control group, while the administration of $O H A E$ significantly reduced these values. AST, ALT, and ALP are enzymes found highly concentrated in the liver, so the elevation of these serum parameters may be a precious indicator of liver injuries [50-53]. Elevation of these enzymes in serum may be partly due to the disruption of hepatocytes membrane integrity and leakage of these enzymes into the systemic circulation $[54,55]$.

Various mechanisms are defined for lead toxicity, but it seems that oxidative stress induced by lead accumulation is the most crucial reason for lead toxicity $[16,56]$. Our in vivo study also showed that administration of lead acetate significantly developed oxidative stress mechanisms by the significant increment of MDA and, on the contrary, a significant decrement of serum catalase activity. In contrast, $O H A E$ significantly reduced the serum content of MDA and increased catalase activity. An increase in MDA level as an indicator of lipid peroxidation and a decrease in catalase activity in serum are essential indicators of free radicals' production and provide an imbalance of oxidant/antioxidant system leading to lipid peroxidation in cell membranes of hepatocytes [57-61]. Therefore, impairment of cell membrane integrity of hepatocytes and leakage of transaminases and ALP in the serum in our study may be due to free radical interaction with the membrane's lipids, especially phospholipids. Previous studies have explained that lead toxicity is associated with liver damages and an elevation in the levels of transaminases and ALP and the histopathological parameters. Oxidative stress is another consequence of lead intoxication [62-68]. The result of these 


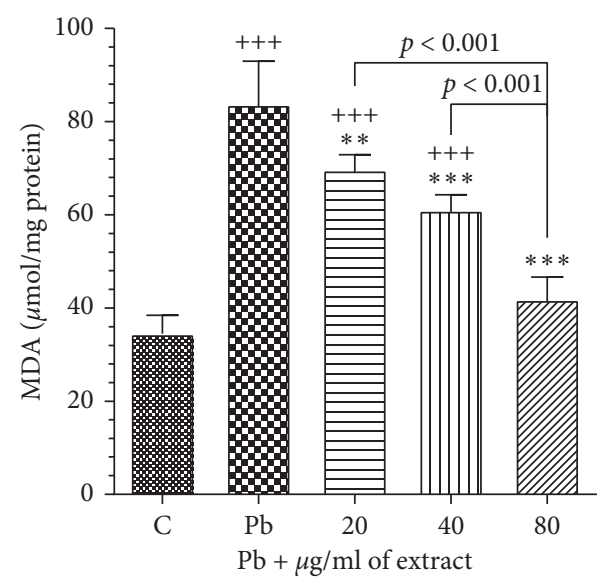

(a)

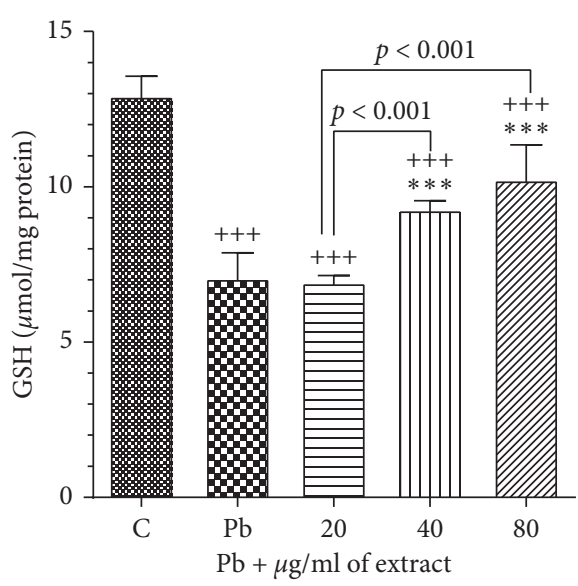

(b)

FIGURE 8: Effect of OHAE at 20,40, and $80 \mu \mathrm{g} / \mathrm{ml}$ on the levels of oxidant and antioxidant parameters (a) MDA and (b) GSH, respectively, following lead toxicity $(100 \mu \mathrm{g} / \mathrm{ml})$. Values are expressed as mean \pm SD. ${ }^{* * *} p<0.001$ and ${ }^{* *} p<0.01$ significant compared to the Pb group; ${ }^{+++} p<0.001$ significant compared to the control group. The lines represent comparisons between extract-treated groups.

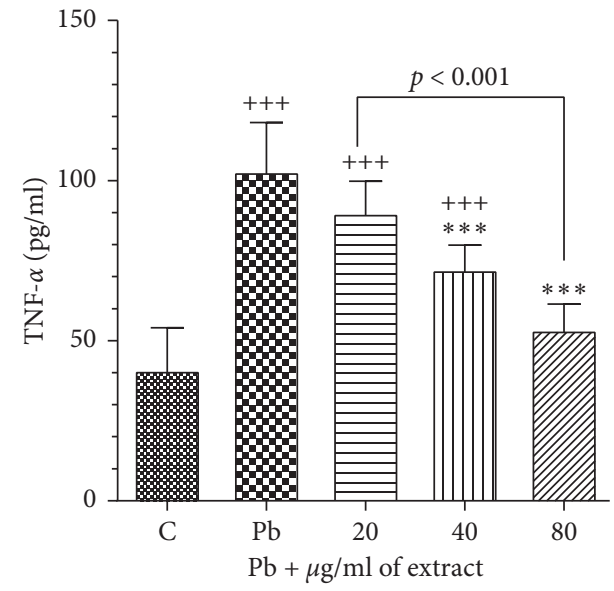

Figure 9: Effect of OHAE at 20, 40, and $80 \mu \mathrm{g} / \mathrm{ml}$ on $\mathrm{Pb}(100 \mu \mathrm{g} / \mathrm{ml})$ induced inflammation. Values are expressed as mean $\pm \mathrm{SD}$. ${ }^{* * * *} p<0.001$ significant compared to the $\mathrm{Pb}$ group; ${ }^{+++} p<0.001$ significant compared to the control group. The lines represent comparisons between extract-treated groups.

studies is concurrent with our study and can support our result regarding the models.

Our study indicated that $O D$ extract $(0-160 \mu \mathrm{g} / \mathrm{ml})$ had no cytotoxicity on the HepG2 cell line. Pretreatment of the lead-exposed cells with the extract $(20-80 \mu \mathrm{g} / \mathrm{ml})$ could significantly retrieve cell viability in a concentration-dependent manner. The result of our study was in concordance with Jelena Katanić et al. that stated that different extracts of $O D$ fruit (from 100 to $500 \mu \mathrm{g} / \mathrm{ml}$ ) had no cytotoxicity on the HepG2 cell line $\left(\mathrm{IC}_{50}>500 \mu \mathrm{g} / \mathrm{ml}\right)$ [69]. In another study, the $O D$ cladodes also showed mild cytotoxic effects on murine macrophage cell line RAW 264.7 at the concentration of $100 \mu \mathrm{M}$ [70]. The fruits of Opuntia robusta and Opuntia streptacantha, two other plants of the Opuntia species, also showed significant protection against acetaminophen-induced cell death in the rat-isolated hepatocytes [71]. Bahira Harrabi and coauthors have also been reported that the polysaccharides obtained from the cladodes of $O D(0-400 \mu \mathrm{g} / \mathrm{ml})$ did not possess any cytotoxicity. Meanwhile, these polysaccharides showed antioxidant activities through inhibition of 1,1-diphenyl-2-picrylhydrazyl (DPPH) and 2,2'-azino-bis(3-ethylbenzothiazoline-6-sulfonic acid (ABTS) radical-induced cytotoxicity at the concentration of $100 \mu \mathrm{g} / \mathrm{mL}$ [72].

Additionally, lead is also known to reduce iron needed for the biosynthesis of heme, leading to the reduction of heme bioavailability and further the reduction of the activity of catalase $[56,73]$. We revealed that $O H A E$ could increase GSH level and catalase activity in both in vitro and in vivo experiments. Nataraj Loganayaki et al., in a study, tried to assess the antioxidant effects of different fruits [74]. They showed that $O D$ fruit has a potent DPPH free radical scavenging activity, which describes plentiful sustainable hydrogen donating and radical scavenging ability $\left(\mathrm{IC}_{50} \approx 43 \mu \mathrm{g} / \mathrm{ml}\right)$ for $O D$ fruit. They also stated that high levels of high molecular weight phenolics (tannins) observed in $O D$ fruit are responsible for this effect [74]. Therefore, the in vitro antioxidant effect of $O H A E$ in our study also is partly due to the high content of these high molecular weight phenolic compounds. We also evaluated the inflammatory status of the HepG2 cell line in the presence or absence of $O D$ extract treatment against $\mathrm{Pb}$-induced toxicity. The result showed that lead acetate provided a significant increment in the level of TNF- $\alpha$, an essential indicator of inflammation [75]. Increased inflammation due to lead administration may be a critical consequence of increased oxidative stress through activation of NF- $\kappa \mathrm{B}[40]$.

$O D$ fruits are composed of valuable chemical constituents with confirmed medicinal applications, including phenolics, betanidin, ascorbic acid, and minerals such as Na, $\mathrm{Ca}, \mathrm{Mg}, \mathrm{Mn}$ and $\mathrm{Cr}, \mathrm{K}, \mathrm{Fe}, \mathrm{Zn}$, and $\mathrm{Ni}$ [20]. Our study showed that $O H A E$ treatments significantly alleviate lead acetate-induced injuries both in vivo and in vitro by reducing the levels of inflammatory and oxidative markers. Previous studies declared that $O D$ fruit is an excellent source of 
betalains, especially betanidin and ascorbic acid, with desirable pharmacologic properties such as antioxidant, antiinflammatory, anticancer, and antilipidemic effects $[20,76,77]$. Ascorbic acid (vitamin C) is known to contribute to carnitine biosynthesis, known as an anti-inflammatory agent $[78,79]$. These data together highlight the antiinflammatory and antioxidant effects of $O D$ that preserve the cell membrane of hepatocytes from further damages [80, 81]. Luisa Tesoriere, in a clinical trial, stated that Opuntia ficusindica, another fruit from the Opuntia family, is more potent than vitamin $\mathrm{C}$ in the reduction of oxidative stress that highlights our findings in the present study [82]. These OD fruits' properties were also studied in previous studies, which are in the same line with the result of our present study $[20,28,77,83,84]$. Phenolic compounds are other valuable compounds that are present in the $O D$ fruits [20].

As limitations of the present study, lactate dehydrogenase $(\mathrm{LDH})$ is an exciting marker to assess liver damage that we did not measure in the present study, suggesting further investigation. Additionally, the effects of lead exposure on hemoglobin heme group synthesis may reduce the functional capacity of cytochrome P-450 in the liver system. Thus, it would be suggested to evaluate the quality if other parameters are related to the production of hemoglobin and hematological changes would be evaluated in future work. In addition to liver damage, the effects of lead exposure on bones, the central and cardiovascular nervous systems, and the kidneys have been reported, which can be considered the extract's protective effects against them.

In conclusion, this study has demonstrated that $O H A E$ significantly reduced lead acetate-induced liver injury, oxidative stress, and inflammation by the view of histopathology, in vivo and in vitro. These effects may be manifold by OD fruits' chemical composition, mainly phenolic, betacyanin, and mineral compounds found in OD fruits, which can be suggested for further consideration in other studies. Taken together, $O D$ extract may have potential protective effects against lead toxicity as herbal medicine after clinical studies.

\section{Abbreviations}

ALP: Alkaline phosphatase

ALT: Alanine aminotransferase

AST: Aspartate aminotransferase

FBS: Fetal bovine serum

GA: Gallic acid

GSH: Glutathione

HepG2: Human liver cancer cell line

i.p.: Intraperitoneal

IHME: Institute for Health Metrics and Evaluation

IL-1 $\beta$ : Interleukin-1beta

IL-6: Interleukin-6

MDA: malondialdehyde

NF- $\kappa$ B: Nuclear factor-kappa B

OD: Opuntia dillenii HAW

OHAE: Opuntia dillenii haw fruit hydroalcoholic extract

TBARS: Thiobarbituric acid reactive substances

TNF- $\alpha$ : Tumor necrosis factor-alpha
WHO: World Health Organization

DPPH: 1,1-diphenyl-2-picrylhydrazyl

ABTS: 2,2'-azino-bis(3-ethylbenzothiazoline-6-sulfonic acid).

\section{Data Availability}

The data will be available by request to the corresponding authors.

\section{Disclosure}

This study was based on the first author's thesis to get his doctorate in veterinary medicine at the University of Zabol. Reza Shirazinia, Ali Akbar Golabchifar, and Vafa Baradaran Rahimi are the co-first author.

\section{Conflicts of Interest}

There are no conflicts of interest.

\section{Authors' Contributions}

Reza Shirazinia, Ali Akbar Golabchifar, and Vafa Baradaran Rahimi contributed equally.

\section{Acknowledgments}

The authors are grateful to the University of Zabol for financial support. The authors also thank Dr. Elyas Zeinali for technical support.

\section{References}

[1] N. Loh, H.-P. Loh, L. K. Wang, and M.-H. Sung Wang, "Health effects and control of toxic lead in the environment," in Natural Resources and Control Processes, pp. 233-284, Springer, Berlin, Germany, 2016.

[2] D. Ford, V. Margaritis, and A. Mendelsohn, "Characteristics of childhood lead poisoning among Tennessee children ages one to five years, 2009-2013," Public Health, vol. 136, pp. 188-191, 2016.

[3] J. Liang and J.-s. Mao, "Risk assessment of lead emissions from anthropogenic cycle," Transactions of Nonferrous Metals Society of China, vol. 26, no. 1, pp. 248-255, 2016.

[4] World Health Organization, Lead Poisoning and Health, World Health Organization, Geneva, Switzerland, 2019, https://www. who.int/news-room/fact-sheets/detail/lead-poisoning-and-health.

[5] M. Méndez, A. Battocletti, A. Sosa, D. Pose, M. J. Moll, and A. Laborde, "Blood lead levels and potential sources of lead exposure among children in Montevideo, Uruguay," Toxicology Letters, vol. 259, no. 259, p. S170, 2016.

[6] M. A. Assi, M. N. M. Hezmee, A. W. Haron, M. Y. Sabri, and M. A. Rajion, "The detrimental effects of lead on human and animal health," Veterinary World, vol. 9, no. 6, pp. 660-671, 2016.

[7] A. L. Wani, A. Ara, and J. A. Usmani, "Lead toxicity: a review," Interdisciplinary Toxicology, vol. 8, no. 2, pp. 55-64, 2015.

[8] P. Álvarez-Lloret, C. M. Lee, M. I. Conti, A. R. Terrizzi, S. González-López, and M. P. Martínez, "Effects of chronic lead exposure on bone mineral properties in femurs of growing rats," Toxicology, vol. 377, pp. 64-72, 2017. 
[9] B. M. Jarrar, "Histological and histochemical alterations in the liver induced by lead chronic toxicity," Saudi Journal of Biological Sciences, vol. 19, no. 2, pp. 203-210, 2012.

[10] E. Taib, K. Chibowska, I. Gutowska et al., "Lead (Pb) exposure enhances expression of factors associated with inflammation," International Journal of Molecular Sciences, vol. 19, no. 6, p. 1813,2018

[11] C. Chen, B. Lin, S. Qi, J. He, and H. Zheng, "Protective effects of salidroside on lead acetate-induced oxidative stress and hepatotoxicity in sprague-Dawley rats," Biological Trace Element Research, vol. 191, no. 2, pp. 426-434, 2019.

[12] B. Al-Ubaidy, DK. Al-Khashali, and NA. Numan, "The role of oxidative stress in lead poisoning," Iraqi Journal of Pharmaceutical Sciences, vol. 15, no. 1, pp. 68-73, 2017.

[13] V. R. Askari, S. A. Rezaee, K. Abnous, M. Iranshahi, and M. H. Boskabady, "The influence of hydro-ethanolic extract of Portulaca oleracea L. on Th1/Th2 balance in isolated human lymphocytes," Journal of Ethnopharmacology, vol. 194, pp. 1112-1121, 2016.

[14] T. Farkhondeh, M. Boskabady, M. Koohi, G. Sadeghi-Hashjin, and M. Moin, "The effect of lead exposure on selected blood inflammatory biomarkers in guinea pigs," Cardiovascular \& Hematological Disorders-Drug Targets, vol. 13, no. 1, pp. 4549, 2013.

[15] C.-M. Liu, Y.-Z. Sun, J.-M. Sun, J.-Q. Ma, and C. Cheng, "Protective role of quercetin against lead-induced inflammatory response in rat kidney through the ROS-mediated MAPKs and NF- $\kappa$ B pathway," Biochimica et Biophysica Acta (BBA)-General Subjects, vol. 1820, no. 10, pp. 1693-1703, 2012.

[16] G. Flora, D. Gupta, and A. Tiwari, "Toxicity of lead: a review with recent updates," Interdisciplinary Toxicology, vol. 5, no. 2, pp. 47-58, 2012.

[17] A. J. Trevor, B. G. Katzung, M. M. Kruidering-Hall, and S. B. Masters, Pharmacology Examination \& Board Review, McGraw-Hill Medical, New York, NY, USA, 2010.

[18] D. J. Balestra, "Adult chronic lead intoxication. A clinical review," Archives of Internal Medicine, vol. 151, no. 9, pp. 1718-1720, 1991.

[19] L. C. Majure, R. Puente, M. P. Griffith, W. S. Judd, P. S. Soltis, and D. E. Soltis, "Phylogeny of Opuntias. s. (Cactaceae): clade delineation, geographic origins, and reticulate evolution," American Journal of Botany, vol. 99, no. 5, pp. 847-864, 2012.

[20] R. Shirazinia, V. Baradaran Rahimi, A. Kehkhaie, A. Sahebkar, H. Rakhshandeh, and V. Askari, "Opuntia dillenii: a forgotten plant with promising pharmacological properties," Journal of Pharmacopuncture, vol. 22, no. 1, pp. 16-27, 2019.

[21] T. Shah, V. R. Nimavat, U. D. Patel et al., "Protective effect of Opuntia elatior and Withania somnifera against lead acetate induced toxicity in broiler chickens," The Indian Journal of Veterinary Sciences and Biotechnology, vol. 11, pp. 1-5, 2016.

[22] J. M. Feugang, P. Konarski, D. Zou, F. C. Stintzing, and C. Zou, "Nutritional and medicinal use of Cactus pear (Opuntia spp.) cladodes and fruits," Frontiers in Bioscience, vol. 11, no. 1, pp. 2574-2589, 2006.

[23] Y. Qiu, D. Dou, Y. Pei, M. Yoshikawa, H. Matsuda, and Y. Chen, "Study on chemical constituents from Opuntia dillenii," Zhongguo Zhong Yao Za Zhi= Zhongguo Zhongyao Zazhi= China Journal of Chinese Materia Medica, vol. 30, no. 23, pp. 1824-1826, 2005.

[24] M. Aragona, E. R. Lauriano, S. Pergolizzi, and C. Faggio, "Opuntia ficus-indica (L.) Miller as a source of bioactivity compounds for health and nutrition," Natural Product Research, vol. 32, no. 17, pp. 2037-2049, 2018.
[25] Y. A. E. I. Nougbodé, C. P. Agbangnan, A. Y. Koudoro et al., "Evaluation of the opuntia dillenii as natural coagulant in water clarification: case of treatment of highly turbid surface water," Journal of Water Resource and Protection, vol. 05, no. 12, pp. 1242-1246, 2013.

[26] P. Mane, A. S. Bhosle, C. Jangam, and S. Mukate, "Heavy metal removal from aqueous solution by opuntia: a natural polyelectrolyte," Journal of Natural Product and Plant Resources, vol. 1, pp. 75-80, 2011.

[27] L. Y. Zhao, S.-L. Zhang, Q.-X. Yuan, J. Cheng, and F.-H. Zeng, "Immunomodulatory effects of Opuntia dillenii polysaccharides on specific immune function of mice," Zhong Yao Cai, vol. 35, no. 1, pp. 98-102, 2012.

[28] J. F. Loro, I. del Rio, and L. Pérez-Santana, "Preliminary studies of analgesic and anti-inflammatory properties of Opuntia dillenii aqueous extract," Journal of Ethnopharmacology, vol. 67, no. 2, pp. 213-218, 1999.

[29] Q. Yang, H. Chen, X. Zhou, and J. Zhang, "Optimum extraction of polysaccharides from Opuntia dillenii and evaluation of its antioxidant activities," Carbohydrate Polymers, vol. 97, no. 2, pp. 736-742, 2013.

[30] X. Huang, Q. Li, H. Li, and L. Guo, "Neuroprotective and antioxidative effect of cactus polysaccharides in vivo and in vitro," Cellular and Molecular Neurobiology, vol. 29, no. 8, pp. 1211-1221, 2009.

[31] M. Perfumi and R. Tacconi, "Antihyperglycemic effect of fresh opuntia dillenii fruit from tenerife (canary Islands)," International Journal of Pharmacognosy, vol. 34, no. 1, pp. 41-47, 1996.

[32] W. Li, D. Wu, B. Wei et al., "Anti-tumor effect of cactus polysaccharides on lung squamous carcinoma cells (SK-MES1)," African Journal of Traditional, Complementary and Alternative Medicines, vol. 11, no. 5, pp. 99-104, 2014.

[33] R. Saleem, M. Ahmad, A. Azmat et al., "Hypotensive activity, toxicology and histopathology of opuntioside-I and methanolic extract of Opuntia dillenii," Biological and Pharmaceutical Bulletin, vol. 28, no. 10, pp. 1844-1851, 2005.

[34] M. I. Umar, A. Javeed, M. Ashraf et al., "Polarity-based solvents extraction ofOpuntia dilleniiandZingiber officinaleforIn VitroAntimicrobial activities," International Journal of Food Properties, vol. 16, no. 1, pp. 114-124, 2013.

[35] O. J. Banji, D. Banji, and R. Kavitha, "Immunomodulatory effects of alcoholic and hydroalcoholic extracts of moringa olifera lam leaves," Indian Journal of Experimental Biology, vol. 50, no. 4, pp. 270-276, 2012.

[36] R. Shirazinia, H. M. Reza, J. Abbas, S. K. Ali Reza, and H. Parisa, "Effects of averrhoa carambola hydro-alcoholic extract on acute lead-acetate-induced liver toxicity in rats," Journal of Isfahan Medical School (IUMS), vol. 34, no. 411, pp. 1531-1536, 2017.

[37] E. A. Ainsworth and K. M. Gillespie, "Estimation of total phenolic content and other oxidation substrates in plant tissues using Folin-Ciocalteu reagent," Nature Protocols, vol. 2, no. 4, pp. 875-877, 2007.

[38] M. R. Rover and R. C. Brown, "Quantification of total phenols in bio-oil using the Folin-Ciocalteu method," Journal of Analytical and Applied Pyrolysis, vol. 104, pp. 366-371, 2013.

[39] V. R. Askari, V. B. Rahimi, P. Zamani et al., "Evaluation of the effects of Iranian propolis on the severity of post operationalinduced peritoneal adhesion in rats," Biomedicine \& Pharmacotherapy, vol. 99, pp. 346-353, 2018.

[40] V. B. Rahimi, R. Shirazinia, N. Fereydouni et al., "Comparison of honey and dextrose solution on post-operative peritoneal 
adhesion in rat model," Biomedicine \& Pharmacotherapy, vol. 92, pp. 849-855, 2017.

[41] H. M. Abdou and M. A. Hassan, "Protective role of omega-3 polyunsaturated fatty acid against lead acetate-induced toxicity in liver and kidney of female rats," BioMed Research International, vol. 2014, 2014.

[42] V. B. Rahimi, V. R. Askari, A. Mehrdad, and H. R. Sadeghnia, "Boswellia serrata has promising impact on glutamate and quinolinic acid-induced toxicity on oligodendroglia cells: in vitro study," Acta Poloniae Pharmaceutica, vol. 74, no. 6, pp. 1803-1811, 2017.

[43] M. Abu-Amara, S. Y. Yang, A. Quaglia et al., "Effect of remote ischemic preconditioning on liver ischemia/reperfusion injury using a new mouse model," Liver Transplantation, vol. 17, no. 1, pp. 70-82, 2011.

[44] W. Sukketsiri, S. Porntadavity, L. Phivthong-ngam, and S. Lawanprasert, "Lead inhibits paraoxonase 2 but not paraoxonase 1 activity in human hepatoma HepG2 cells," Journal of Applied Toxicology, vol. 33, no. 7, pp. 631-637, 2013.

[45] V. R. Askari, V. B. Rahimi, A. Ghorbani, and H. Rakhshandeh, "Hypnotic effect of ocimum basilicum on pentobarbital-induced sleep in mice," Iranian Red Crescent Medical Journal, vol. 18, no. 7, Article ID e24261, 2016.

[46] W. H. El-Tantawy, "Antioxidant effects of Spirulina supplement against lead acetate-induced hepatic injury in rats," Journal of Traditional and Complementary Medicine, vol. 6, no. 4, pp. 327-331, 2016.

[47] Q. Jia, X. Ha, Z. Yang, L. Hui, and X. Yang, "Oxidative stress: a possible mechanism for lead-induced apoptosis and nephrotoxicity," Toxicology Mechanisms and Methods, vol. 22, no. 9, pp. 705-710, 2012.

[48] A. A. El-Nekeety, A. A. El-Kady, M. S. Soliman, N. S. Hassan, and M. A. Abdel-Wahhab, "Protective effect of Aquilegia vulgaris (L.) against lead acetate-induced oxidative stress in rats," Food and Chemical Toxicology, vol. 47, no. 9, pp. 2209-2215, 2009.

[49] A. Mudipalli, "Lead hepatotoxicity \& potential health effects," Indian Journal of Medical Research, vol. 126, no. 6, p. 518, 2007.

[50] E. G. Giannini, R. Testa, and V. Savarino, "Liver enzyme alteration: a guide for clinicians," Canadian Medical Association Journal, vol. 172, no. 3, pp. 367-379, 2005.

[51] S. R. Puranik, J. S. Hayes, J. Long, and M. Mata, "Liver enzymes as predictors of liver damage due to blunt abdominal trauma in children," Southern Medical Journal, vol. 95, no. 2, pp. 203-206, 2002.

[52] N. A. Stassen, J. K. Lukan, E. H. Carrillo et al., "Examination of the role of abdominal computed tomography in the evaluation of victims of trauma with increased aspartate aminotransferase in the era of focused abdominal sonography for trauma," Surgery, vol. 132, no. 4, pp. 642-647, 2002.

[53] Y. J. Kim, "Interpretation of liver function tests," The Korean Journal of Gastroenterology, vol. 51, no. 4, pp. 219-224, 2008.

[54] Z. Tian, H. Liu, X. Su et al., "Role of elevated liver transaminase levels in the diagnosis of liver injury after blunt abdominal trauma," Experimental and Therapeutic Medicine, vol. 4, no. 2, pp. 255-260, 2012.

[55] P. F. Solter, "Clinical pathology approaches to hepatic injury," Toxicologic Pathology, vol. 33, no. 1, pp. 9-16, 2005.

[56] J. Wang, H. Zhu, Z. Yang, and Z. Liu, "Antioxidative effects of hesperetin against lead acetate-induced oxidative stress in rats," Indian Journal of Pharmacology, vol. 45, no. 4, pp. 395-398, 2013.
[57] S. Gaweł, M. Wardas, E. Niedworok, and P. Wardas, "Malondialdehyde (MDA) as a lipid peroxidation marker," Wiad Lek, vol. 57, no. 9-10, pp. 453-455, 2004.

[58] W. X. Ding, H. M. Shen, Y. Shen, H. G. Zhu, and C. N. Ong, "Microcystic cyanobacteria causes mitochondrial membrane potential alteration and reactive oxygen species formation in primary cultured rat hepatocytes," Environmental Health Perspectives, vol. 106, no. 7, pp. 409-413, 1998.

[59] S. J. Hermansky, S. J. Stohs, R. S. Markin, and W. J. Murray, "Hepatic lipid peroxidation, sulfhydryl status, and toxicity of the blue-green algal toxin microcystin-LR in mice," Journal of Toxicology and Environmental Health, vol. 31, no. 1, pp. 71-91, 1990.

[60] I. Moreno, S. Pichardo, A. Jos et al., "Antioxidant enzyme activity and lipid peroxidation in liver and kidney of rats exposed to microcystin-LR administered intraperitoneally," Toxicon, vol. 45, no. 4, pp. 395-402, 2005.

[61] A. Catalá and M. Díaz, "Editorial: impact of lipid peroxidation on the physiology and pathophysiology of cell membranes," Frontiers in Physiology, vol. 7, no. 423, 2016.

[62] N. M. Ibrahim, E. A. Eweis, H. S. El-Beltagi, and Y. E. AbdelMobdy, "Effect of lead acetate toxicity on experimental male albino rat," Asian Pacific Journal of Tropical Biomedicine, vol. 2, no. 1, pp. 41-46, 2012.

[63] S. A. H. Kadhum, "Effect of different dosage from lead acetate administrated on the liver enzymes and histopathilogical of liver in white male rats," Journal of Pharmaceutical Sciences and Research, vol. 11, no. 4, pp. 1657-1661, 2019.

[64] S. Moussa and S. Bashandy, "Biophysical and biochemical changes in the blood of rats exposed to lead toxicity," Rom J Biophys, vol. 18, no. 2, pp. 123-133, 2008.

[65] I. M. El-Ashmawy, A. F. El-Nahas, and O. M. Salama, "Protective effect of volatile oil, alcoholic and aqueous extracts of origanum majorana on lead acetate toxicity in mice," Basic Clinical Pharmacology Toxicology, vol. 97, no. 4, pp. 238-243, 2005.

[66] P. Hasanein, A. Kazemian-Mahtaj, and I. Khodadadi, "Bioactive peptide carnosin protects against lead acetate-induced hepatotoxicity by abrogation of oxidative stress in rats," Pharmaceutical Biology, vol. 54, no. 8, pp. 1458-1464, 2016.

[67] G. H. El-Sokkary, G. H. Abdel-Rahman, and E. S. Kamel, "Melatonin protects against lead-induced hepatic and renal toxicity in male rats," Toxicology, vol. 213, no. 1-2, pp. 25-33, 2005.

[68] R. Baty, K. Hassan, K. Alsharif et al., "Neuroprotective role of luteolin against lead acetate-induced cortical damage in rats," Human \& Experimental Toxicology, vol. 39, no. 9, pp. 12001212, 2020.

[69] J. Katanić, F. Yousfi, M. C. Caruso et al., "Characterization of bioactivity and phytochemical composition with toxicity studies of different Opuntia dillenii extracts from Morocco," Food Bioscience, vol. 30, Article ID 100410, 2019.

[70] O. Izuegbuna, G. Otunola, and G. Bradley, "Chemical composition, antioxidant, antiinflammatory, and cytotoxic activities of Opuntia stricta cladodes," PLoS One, vol. 14, no. 1, Article ID e0209682, 2019.

[71] H. González-Ponce, M. Martínez-Saldaña, A. Rincón-Sánchez et al., "Hepatoprotective effect of opuntia robusta and opuntia streptacantha fruits against acetaminophen-induced acute liver damage," Nutrients, vol. 8, no. 10, p. 607, 2016.

[72] B. Harrabi, K. Athmouni, L. Hamdaoui et al., "Polysaccharides extraction from Opuntia stricta and their protective effect against HepG2 cell death and hypolipidaemic effects on hyperlipidaemia rats induced by high-fat diet," Archives of 
Physiology and Biochemistry, vol. 123, no. 4, pp. 225-237, 2017.

[73] M. T. Antonio-García and E. L. Massó-Gonzalez, "Toxic effects of perinatal lead exposure on the brain of rats: involvement of oxidative stress and the beneficial role of antioxidants," Food and Chemical Toxicology, vol. 46, no. 6, pp. 2089-2095, 2008.

[74] N. Loganayaki and S. Manian, "In vitro antioxidant properties of indigenous underutilized fruits," Food Science and Biotechnology, vol. 19, no. 3, pp. 725-734, 2010.

[75] H. Zelová and J. Hošek, "TNF- $\alpha$ signalling and inflammation: interactions between old acquaintances," Inflammation Research, vol. 62, no. 7, pp. 641-651, 2013.

[76] W. S. Choo, "Betalains: application in functional foods," in Bioactive Molecules in Food, J.-M. Mérillon and K. G. Ramawat, Eds., pp. 1-28, Springer International Publishing, Cham, Switzerland, 2017.

[77] C. Betancourt, M. J. Cejudo-Bastante, F. J. Heredia, and N. Hurtado, "Pigment composition and antioxidant capacity of betacyanins and betaxanthins fractions of Opuntia dillenii (Ker Gawl) Haw cactus fruit," Food Research International, vol. 101, pp. 173-179, 2017.

[78] H. E. Sauberlich, "Pharmacology of vitamin C," Annual Review of Nutrition, vol. 14, no. 1, pp. 371-391, 1994.

[79] B.-J. Lee, J.-S. Lin, Y.-C. Lin, and P.-T. Lin, "Antiinflammatory effects of L-carnitine supplementation (1000 mg/ d) in coronary artery disease patients," Nutrition, vol. 31, no. 3, pp. 475-479, 2015.

[80] J. V. Castell, M. J. Gómez-Lechón, X. Ponsoda, and R. Bort, "16-in vitro investigation of the molecular mechanisms of hepatotoxicity," in In Vitro Methods in Pharmaceutical Research, J. V. Castell and M. J. Gómez-Lechón, Eds., pp. 375-410, Academic Press, San Diego, CA, USA, 1997.

[81] S. A. Jancic and BZ. Stosic, "Chapter fourteen-cadmium effects on the thyroid gland," in Vitamins \& Hormones, G. Litwack, Ed., pp. 391-425, Academic Press, Cambridge, MA, USA, 2014.

[82] L. Tesoriere, D. Butera, A. M. Pintaudi, M. Allegra, and M. A. Livrea, "Supplementation with cactus pear (Opuntia ficus-indica) fruit decreases oxidative stress in healthy humans: a comparative study with vitamin C," The American Journal of Clinical Nutrition, vol. 80, no. 2, pp. 391-395, 2004.

[83] M. S. Ahmed, N. D. E. Tanbouly, W. T. Islam, A. A. Sleem, and A. S. E. Senousy, "Antiinflammatory flavonoids from Opuntia dillenii (Ker-Gawl) Haw. flowers growing in Egypt,” Phytotherapy Research, vol. 19, no. 9, pp. 807-809, 2005.

[84] S.-F. Chang, C.-L. Hsieh, and G.-C. Yen, "The protective effect of Opuntia dillenii Haw fruit against low-density lipoprotein peroxidation and its active compounds," Food Chemistry, vol. 106 , no. 2 , pp. 569-575, 2008. 